\title{
The optimization of a potential geothermal reservoir using abandoned wells: a case study for the forest reserve field in Trinidad
}

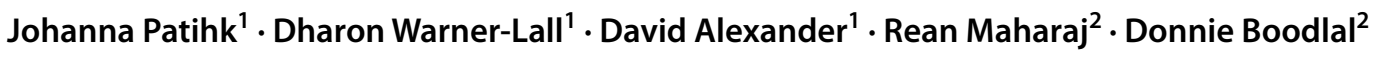

Received: 22 June 2021 / Accepted: 29 September 2021 / Published online: 12 October 2021

(c) The Author(s) 2021

\begin{abstract}
The worldwide dependence on non-renewable energy sources continues as existing energy systems have been built on these supplies. There is an established link between these conventional energy resources, greenhouse gas (GHG) emissions and climate change and its associated negative effects. As a signatory to the Paris Agreement, Trinidad and Tobago (TT) has been exploring strategies to reduce GHG emissions and the use of geothermal energy is one potential option. Through enhanced geothermal systems, TT, even without extensive volcanic heat reservoirs, can still develop this renewable source by utilizing oil reservoirs. This study evaluates the possibility of designing and evaluating geothermal systems using wells from the Forest Reserve fields in South-western Trinidad as a case study. The Forest Reserve fields have a high number of abandoned oil and gas wells which can be re-used for tapping the required heat and reducing the requirement for drilling of new injection and production geothermal wells. Key information and data from these wells and reservoirs were used as input for CMG software to model, design and evaluate the feasibility of the geothermal reservoir and wells as being possible and viable for geothermal production. A base model was constructed in the CMG software which was subjected to three essential manual sensitivity analyses (well distance, stream temperature, and injection pressure) to obtain an optimized model which was then subjected to hydraulic fracturing. The optimal model of the retrofitted geothermal systems demonstrated to be the best case scenario due to the shallow nature of the reservoir in the area of interest. Six retrofitted geothermal systems ( 3 injector wells and 3 producer wells) showed that capable capacity of $3.3721 \mathrm{MWe}$ for a 25 -year period with an Internal Rate of Return of $190 \%$ and an Net Present Value of US\$1,431,263,840.00 utilizing a Minimum Acceptable Rate of Return of 10\%, Capital Expenditure of US\$12MM, Operating Expenditure of US\$2MM and a cost of geothermal electricity at US\$0.05 per kWh. These results were then used in Crystal Ball to apply Monte Carlo simulations where it confirmed that the project is 100\% economically feasible. The cumulative carbon dioxide reduction after the 25 -year period was $50,062,500$ tons of $\mathrm{CO}_{2}$.
\end{abstract}

Keywords Climate change $\cdot$ Geothermal systems $\cdot$ Hydraulic fracturing $\cdot$ Sensitivity analysis

\section{Introduction}

The demand for energy from cleaner sources resulting from climate agreements and their associated targets has led countries to explore different energy options. The development of geothermal energy for electricity generation and predominantly the use of enhanced geothermal systems (EGS) are encouraging options, and it has the potential to be a major

Rean Maharaj

rean.maharaj@utt.edu.tt

1 Energy Systems Engineering Unit, University of Trinidad and Tobago, Couva, Trinidad and Tobago

2 Process Engineering Unit, University of Trinidad and Tobago, Couva, Trinidad and Tobago contributor in the future for energy sustainability according to the American Geoscience Institute (American Geosciences Institute 2020).

TT is located in the Southern Caribbean and has been producing oil and gas for over 100 years; however the hydrocarbon reserves have been steadily decreasing. According to the Worldmeter (Worldmeter 2021) in 1980, TTs average daily production was 200,000 barrels per day and today production has plummeted to roughly 55,000 barrels per day forcing the need for economic diversification away from hydrocarbons (Oil Now 2020). Industrialization in TT has resulted in the country having the second-highest per capita carbon dioxide emissions in the world which is about 6 times that of the world average (Indar 2019). Given TT's large carbon dioxide footprint, a reduction in emissions has

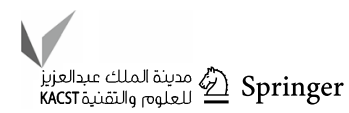


become a major issue regarding attention (Indar 2019). For more than 100 years, Trinidad and Tobago (TT) has been producing oil and gas and utilizes this as its main source of energy. According to Energy Snapshot (Energy Snapshot 2015), TT enjoys the lowest rates of electricity of US $\$ 0.04$ per kilowatt-hour $(\mathrm{kWh})$, due to applied subsidies on electricity by the government, while the rest of the Caribbean islands' rates are an average of US $\$ 0.33$ per $\mathrm{kWh}$. It is suggested that without subsidies, the actual cost of electricity in TT would be $\$ 0.12$ per $\mathrm{kWh}$ and that rates are set to rise (Chamber 2021) (Govinda Hosien 2020). As oil and gas production have steadily declined over the years, TT is currently considering removing these subsidies in an effort to make cleaner energy projects more feasible.

In keeping with TT Government's Vision 2030 (Government of Trinidad and Tobago 2015), the Government has set an initial specific target for renewable energy of $10 \%$ of power generation by 2021 which is likely to grow further in an effort to reduce the emission of greenhouse gases which are very harmful to the air necessary for sustaining life (Marzolf 2015). This study will examine the possibility of using geothermal energy as a renewable source of energy for producing electric energy. The study will show the feasibility of TT adopting this method, similar to other countries in the world where the use of enhanced geothermal greatly increased their capability of producing geothermal energy.

Although TT does not have conventional geothermal reservoirs like the neighbouring Lesser Antilles, the island has mud volcanoes and abandoned oil and gas wells that can be retrofitted to harness geothermal energy. The fields of Heritage Petroleum Company Limited (Heritage), formerly Petroleum Company of TT Limited (Petrotrin) contain approximately 5000 abandoned wells in fields throughout the southern part of the island of Trinidad. These wells are ideal candidates for enhanced geothermal projects once the bottom-hole temperature is suitable, at least 40 to 73 degrees Centigrade and more importantly, the well bore integrity is in good order with the production capacity being suitable for the injection and production well requirement for EGS (Yao 2019). There are hundreds of abandoned oil wells at Forest Reserve (see Fig. 1), which have shut-in temperatures of approximately $100-115^{\circ} \mathrm{C}\left(212-239^{\circ} \mathrm{F}\right)$; a temperature gradient required for EGS applications.

The use of abandoned oil and gas wells was found to be economically feasible as drilling cost can account for 42 to $95 \%$ of the total cost for an enhanced geothermal system (Tester 1994). These wells will already have data on the lithology of the reservoirs, there are no drilling costs, projects using these wells avoid disrupting the environment (Yao 2019). Utilizing abandoned oil and gas wells near metropolitan zones would be least disruptive to communities (Sliwa 2014). Caulk and Tomac (Caulk 2017). Geothermal energy has been harnessed at locations with hydrogeological features (Caulk 2009). The depths of $1000 \mathrm{~m}$ together with thermal gradients between 4 and 7.3 degrees Centigrade per $100 \mathrm{~m}$ with bottom-hole temperatures between 40 and 73 degrees Centigrade exist in the abandoned wells in California, which are similar to the local Forest Reserve wells proposed in this study (Caulk 2009). Researchers developed their own mathematical model for enhanced geothermal systems or deep Borehole Heat Exchanger applications. Their model examined wells of depth $1000 \mathrm{~m}$ where it was shown that production fluids temperature can be higher than 40 degrees Centigrade with temperature gradients of up to 7 degrees Centigrade per $100 \mathrm{~m}$. These parameters would allow low temperature direct use of enhanced geothermal systems for household heating, greenhouse heating and aquaculture use. There exist other examples of EGS feasibility
Fig. 1 Flow Chart outlining the Methodology

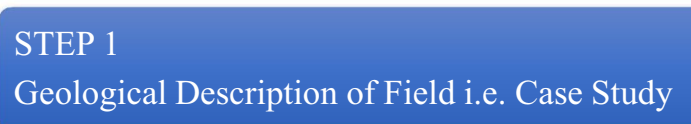

Geological Description of Field i.e. Case Study

STEP 2

Mathematical Models used in the designing of the 3D

Geothermal Numerical Model

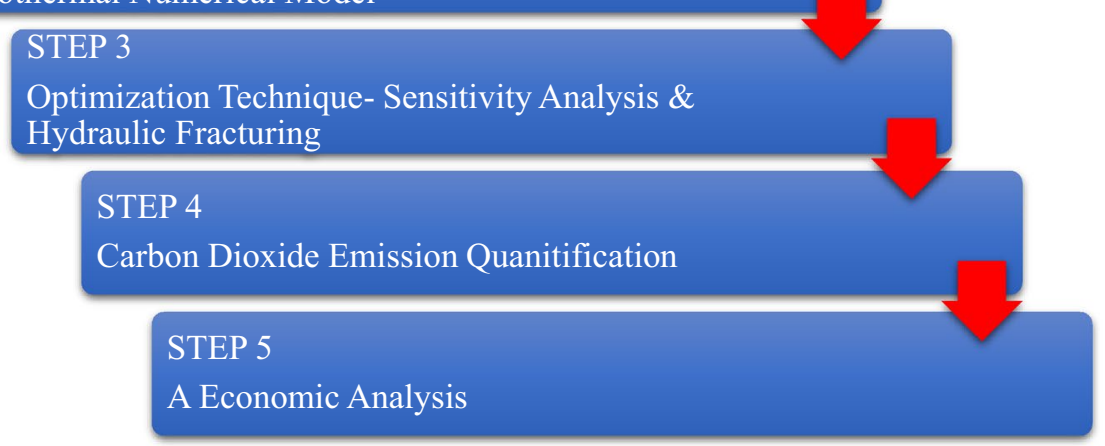




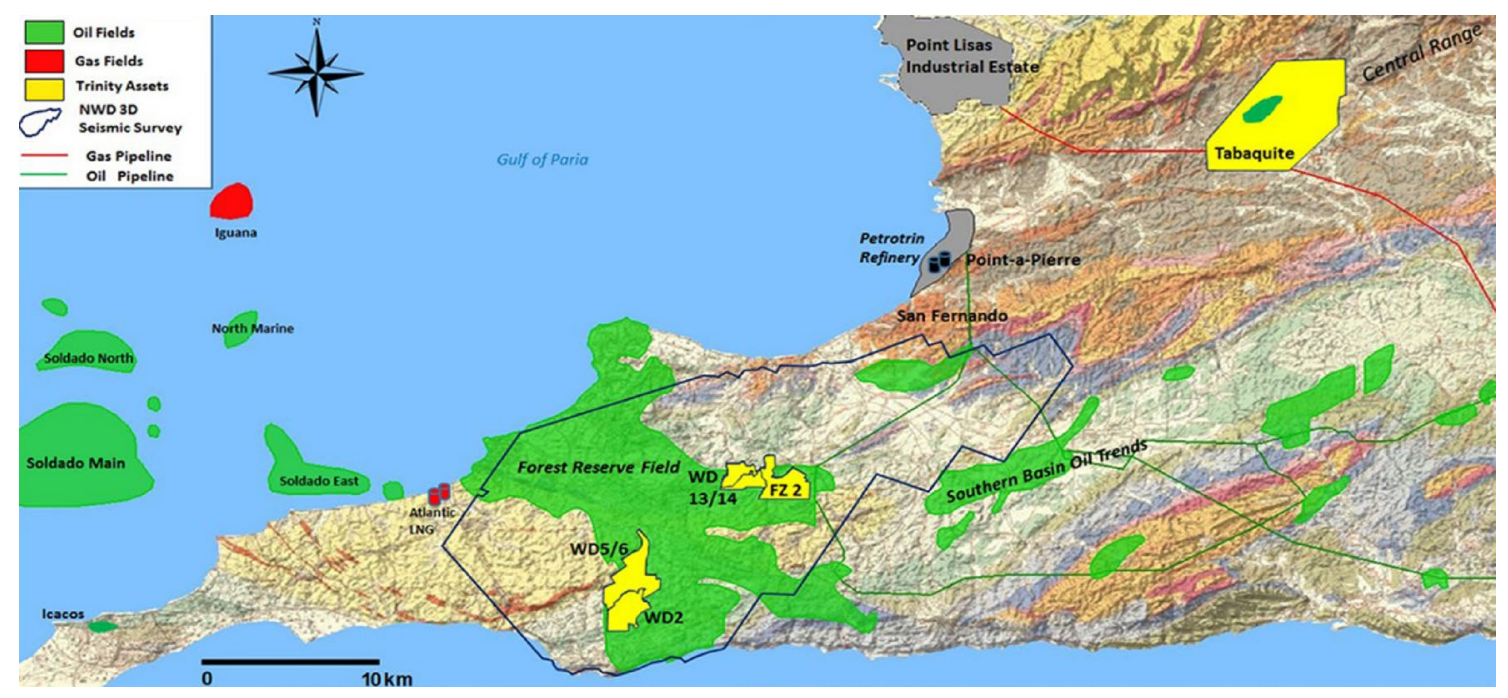

Fig. 2 A map of Southern Trinidad showing the location of Forest Reserve Field (Trinity 2021)

using abandoned hydrocarbon wells (Davis 2009; Bu 2012; Templeton 2014 Nian 2018). Macenic and Kurevija (2017) Zhang (2008). The three (3) main parameters that determine the success of the production of geothermal energy are the temperature of the injected working fluid (water), the injection well pressure, and the distance between the injection well and producer wells (Sanyal and Butler 2005).

This study will involve the design, optimization and evaluation of the feasibility of an EGS for a more sustainable and environmentally friendly renewable energy production method for TT using wells from the Forest Reserve fields in South-western Trinidad as a case study. CMG software will be used to construct and optimize a base model which will be subjected to hydraulic fracturing. The economic feasibility of the optimal model will be evaluated.

\section{Methodology}

The implementation of the use of abandoned hydrocarbon wells is employed in this project. Three (3) injector wells and three (3) producer wells located in Forest Reserve Fields are utilized in the design process of the reservoir to harness the geothermal heat energy. The flow chart shown in Fig. 1 outlines the steps of the methodology.

\section{Field description}

The Forest Reserve field, discovered in 1914, measures approximately 6773.88 acres and has hundreds of abandoned wells. Figure 2 shows a map of Southern Trinidad and the location of the Forest Reserve Field (Trinity 2021).
This area of interest is of upper Miocene to lower Pliocene periods in age and are deltaic in their origin. Structurally, the field is underlain by the western extremity of the East-North-East to West-North-West trending DebeWellington Anticline (Fig. 2). This plunges westward and is dissected by a series of extensional faults which tend to compartmentalize the fields and are sealed at most reservoir levels which can be seen in Figs. 3 and 4. The regional seals and stratigraphic marker horizons across the Forest Reserve field are the Upper Forest Clay and Lower Forest Clay.

\section{Mathematical modelling}

A 3-D geothermal numerical model was designed to study the thermal recovery processes. Local thermal non-equilibrium is assumed. The retrofitted geothermal system utilizes energy equations to build the field temperature of the present fluid contained by the fractured rock matrix. The temperature field can then be employed to depict the method of heat transmission from the real rock-fluid throughout the heat retrieval process.

\section{Mass conservation}

The mass balance equation illustrates the fluid flow through an alterably porous media is set by Eq. 1 (Liang et al. 2016; Zhu 2016).

$S \frac{\partial p}{\partial t}+\nabla \cdot u=-\frac{\partial e}{\partial t}+Q$

In Eq. $1, S, P$, and $t$ signifies the constricted specific storing of the media, pressure, and time, respectively; $e$ signifies 


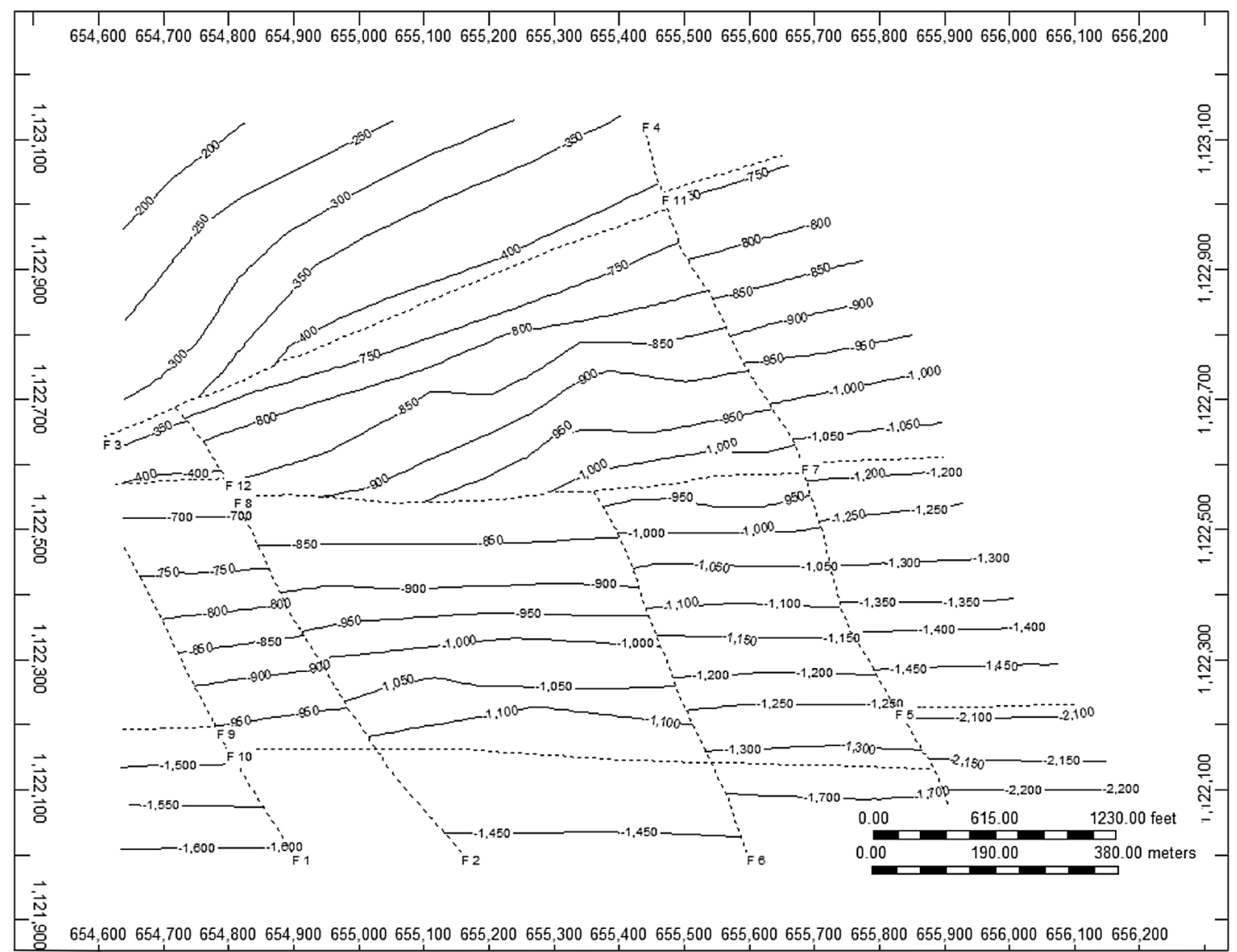

Fig. 3 A Structure Map of the area of interest, Forest Reserve Field

the volumetric strain, and $Q$ signifies the source-sink of the outflow process. The water flow rate, $u$, can be determined by as it complies with Darcy's Law of fluid flow:

$u=-\frac{k}{\mu}\left(\nabla p+\rho_{f} g \nabla z\right)$

where $\kappa$ signifies the permeability of the saturated porous media; $\mu$ and $\rho_{f}$ are dynamic viscosity and fluid density; $g$ is gravitational acceleration; and the unit vector $z$ signifies the course of gravity.

The mass balance equation for fractures is calculated using Eqs. 3 and 4 (Liang et al. 2016; Zhang et al. 2017).

$d_{f} S_{f} \frac{\partial p}{\partial t}+\nabla t \cdot u_{f}=-d_{f} \frac{\partial e f}{\partial t}+Q f$

$u_{f}=-d_{f} \frac{K f}{\mu}\left(\nabla_{t} p+\rho_{f} g \nabla_{t} z\right)$

where $S_{f}, \kappa_{f}, d_{f}$, and $e_{f}$ refer to the specific storage, permeability, thickness, and volumetric strain of the fractures, respectively; $\nabla_{\tau}$ indicates the gradient operator; and $Q_{f}$, represents the fluid flow in the fractures and is given by,

$Q f=-\frac{K f}{\mu} \frac{\partial p}{\partial m}$

where $n$ signifies the standard course of the fracture surface.

\section{The rock mass temperature field}

The velocity of water in the rock matrix will be low as a result of a lowered porosity; thus, the water temperature is assumed to be corresponding to the rock temperature.

$C_{s} \rho_{s} \frac{\partial T s}{\partial t}=\lambda_{s} \nabla^{2} T_{s}+W$

where $\rho_{s}$ is the density of the rock; $\lambda_{\mathrm{s}}$ denotes the rock matrix thermal conductivity; $\mathrm{C}_{\mathrm{s}}$ is the rock heat capacity; " $W$ " signifies the heat exchange occurring in the reservoir; a negative sign refers to heat extracted from the rock, and a positive sign refers to heat captivated by the fluid. 


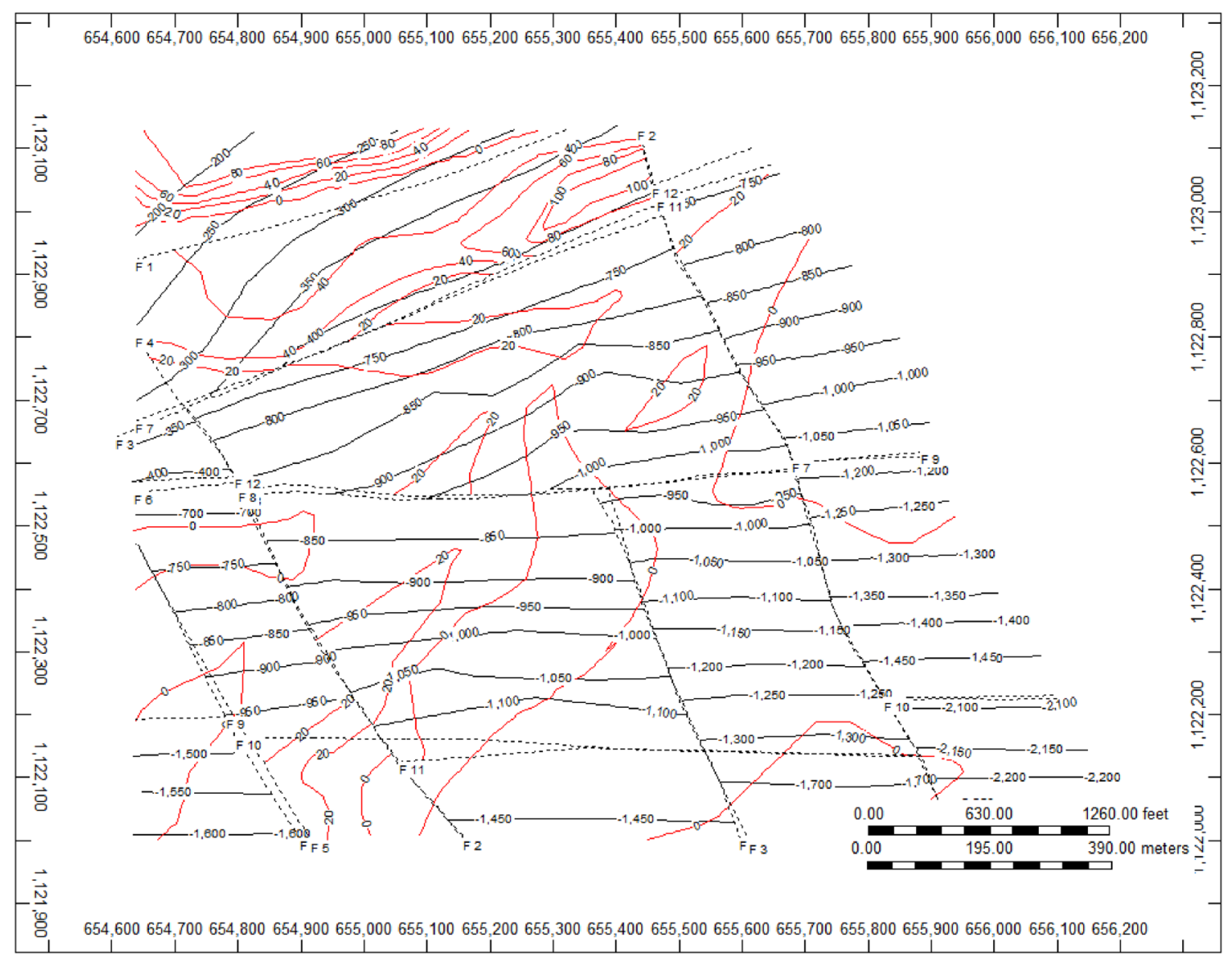

Fig. 4 A Net Oil sand map of the area of interest, Forest Reserve Field

\section{The fracture water temperature field}

$d_{f} \rho_{f} C_{f} \frac{\partial T f}{\partial t}+d_{f} \rho_{f} C_{f} \cdot u_{f} \nabla_{f} T_{f}=d_{f} \nabla_{t} \cdot\left(\lambda_{f} \nabla_{t} T_{f}\right)+W_{f}$

In Eq. $6, \rho_{f}, C_{f}$, and $\lambda_{f}$ are the density, heat capacity, and water thermal conductivity, correspondingly; $u_{f}$ and $T_{f}$ signify the velocity of the water flow and temperature of the water inside the fractures, correspondingly; $W_{f}$ signifies the heat captivated by the water from the matrix block on the fractured surface (Zhang et al. 2017).

Throughout the interchange of heat among the water and the rock matrix and fractures, it is presumed that water follows Newton's law of heat transfer. The heat flow from the rock to the fracture fluid (water per unit area) is described by Eq. 7 (Xu et al. 2015).
$W=h\left(T_{s}-T_{f}\right)$

When the convection efficiency $h$ is sufficiently large, the rock temperature and water temperature become equal at the fracture surface.

\section{Fluid properties under high temperature and pressure}

The coupling effect is related to the fluid properties, and in the deep geothermal reservoirs under high enough temperature and pressure conditions the fluid density $\rho_{f}$ (water density), which can be defined as a function of temperature and pressure (Xu et al. 2015), becomes variable and satisfies:

$1 / \rho_{f}=3.3086-0.899017(4014.15-T)^{0.147166}-0.39(658.15-T)^{-1.6}(p-225.5)+\delta$ 
Table 1 The well parameters (courtesy of Heritage Petroleum Company Ltd.)

\begin{tabular}{ll}
\hline Depth & $2250 \mathrm{ft}$ \\
Well length & $2250 \mathrm{ft}$ \\
Casing length & $2250 \mathrm{ft}$ \\
Insulation length & $2250 \mathrm{ft}$ \\
Tubing size & $0.266 . \mathrm{OD}$ \\
& $(0.166 \mathrm{ft}$. \\
& ID) \\
\hline
\end{tabular}

Table 2 The reservoir properties (courtesy of Heritage Petroleum Company Ltd.)

\begin{tabular}{ll}
\hline Reservoir parameters & Values \\
\hline Depth of reservoir top & $2250 \mathrm{ft}$ \\
Pressure gradient & $0.433 \mathrm{psi} / \mathrm{ft}$ \\
Matrix porosity & $33 \%$ \\
Permeability in I direction & 350 \\
Permeability in J direction & $350 \mathrm{mD}$ \\
Kv/Kh & 0.1 \\
\hline
\end{tabular}

where $\delta$ is a function of water temperature $T$ and pressure $p ; \delta$ generally remains below $6 \%$ of $1 / \rho_{f}$ and influences the dynamic viscosity $\mu=v \rho_{f}$, where $v$ represent the kinematic viscosity of water. The kinematic viscosity is defined by Eq. 9 (W 1983).

$v=\frac{0.01775}{1+0.033 T f+0.000221 T_{f}^{2}}$

The fluid properties are affected by the temperature and can influence the thermal and hydraulic coupling processes within a reservoir.

The justification of a numerical model for thermo-hydraulic analysis has been performed in the previous work (Sun et al. 2017).

\section{Initial and boundary conditions}

Founded on the initial and boundary conditions, the heat production of the retrofitted geothermal system was simulated using the proposed model and the thermal hydraulic coupling analysis was run for 25 years (time step is 1 day). The selected initial and boundary conditions are given below:

Outflow field: To guarantee that water was circulated within the targeted reservoir, the pressure at the injection well was preserved at $1350 \mathrm{psi}$, and the production pressure was 1000 psi.

Thermal field: At the exterior thermal boundaries, the heat flux $\left(Q_{S}\right)$ was constant; however the surface temperature
Table 3 The adopted fracture information

\begin{tabular}{ll}
\hline Fracture information & Values \\
\hline Fracture porosity & 0.0004 \\
Permeability in I direction & $5.0663 \mathrm{mD}$ \\
Permeability in J direction & $5.0663 \mathrm{mD}$ \\
Kv/Kh & 2 \\
Fracture spacing I & $32.8084 \mathrm{ft}$ \\
Fracture spacing J & $32.8084 \mathrm{ft}$ \\
Fracture spacing K & $0 \mathrm{ft}$ \\
\hline
\end{tabular}

Table 4 The adopted properties for the reservoir

\begin{tabular}{ll}
\hline Properties & Values \\
\hline Thermal rock types & \\
Rock compressibility & $0.0000029621 / \mathrm{psi}$ \\
Porosity reference pressure & $974.25 \mathrm{psi}$ \\
Thermal properties & \\
Thermal conductivity reservoir rock & $55.6436565 \mathrm{Btu} /\left(\mathrm{ft} *\right.$ day $\left.{ }^{\circ} \mathrm{F}\right)$ \\
Thermal conductivity water phase & $9.388 \mathrm{Btu} /\left(\mathrm{ft} *\right.$ day $\left.{ }^{\circ} \mathrm{F}\right)$ \\
Overburden heat loss & \\
Volumetric heat capacity & $37.2767 \mathrm{Btu} /\left(\mathrm{ft}^{3}{ }^{\circ} \mathrm{F}\right)$ \\
Thermal conductivity reservoir rock & $55.6436565 \mathrm{Btu} /\left(\mathrm{ft} *\right.$ day $\left.{ }^{\circ} \mathrm{F}\right)$ \\
Under-burden heat loss & \\
Volumetric heat capacity & $37.2767 \mathrm{Btu} /\left(\mathrm{ft}{ }^{3}{ }^{\circ} \mathrm{F}\right)$ \\
Thermal conductivity reservoir rock & $55.6436565 \mathrm{Btu} /\left(\mathrm{ft} *\right.$ day $\left.{ }^{\circ} \mathrm{F}\right)$ \\
\hline
\end{tabular}

Table 5 Adopted reservoir fluids characterization

\begin{tabular}{ll}
\hline Reservoir fluids characterization & Values \\
\hline Critical temperature & $703.103{ }^{\circ} \mathrm{F}$ \\
Molecular weight & $18.02 \mathrm{lb} / \mathrm{lbmole}$ \\
Molar density & $3.46752 \mathrm{lbmole} / \mathrm{ft}^{3}$ \\
Liquid compressibility & $4.82633 \mathrm{E}-061 / \mathrm{psi}$ \\
Thermal expansion coefficient & $0.0004888891 /{ }^{\circ} \mathrm{F}$ \\
\hline
\end{tabular}

at the injection well was $140{ }^{\circ} \mathrm{F}$. The initial temperature in the reservoir was $212{ }^{\circ} \mathrm{F}$ for both water and rock.

\section{Adopted parameters used in the computational processes}

The data presented in Tables 1, 2, 3, 4, 5, 6, 7 show the actual and adopted parameters used in the computational processes.

Appropriate assumptions were made to indicate key parameters and properties necessary to model an enhanced geothermal reservoir with fracturing parameters. 
Table 6 The saturation inputs

\begin{tabular}{llll}
\hline & Sw & krw & krow \\
\hline 1 & 0.01 & 0 & 1 \\
2 & 0.99 & 1 & 0 \\
\hline & SI & krg & krog \\
\hline 1 & 0.01 & 1 & 0 \\
2 & 0.99 & 0 & 1 \\
\hline
\end{tabular}

Table 7 The adopted relative permeability data for the fracture

\begin{tabular}{ll}
\hline Geological Properties & Values \\
\hline OWC & $3000 \mathrm{ft}$ \\
Reservoir rock temperature & $212^{\circ} \mathrm{F}$ \\
Fracture temperature & $212^{\circ} \mathrm{F}$ \\
Reference pressure & $974.25 \mathrm{psi}$ \\
Reference depth & $2250 \mathrm{ft}$ \\
\hline
\end{tabular}

\section{Thermal and hydraulic numerical model and simulation solution}

After applying the initial and boundary conditions, the thermal and hydraulic coupling analysis was carried out and a 3D computational model was constructed based on actual and adopted geological parameters on half the field measuring approximately $3,386.94$ acres $(147,535,106.4$ ft.) which can be observed in Fig. 5.

\section{Thermal retrieval assessment method}

Evans (2010) suggested and estimated the constraints used in the profitable utilization of a thermal reservoir: (1) the minimum reservoir temperature after 25 years of production, the reservoir temperature decline when deprived of restoration; (2) water loss is less than $10 \%$; (3) the volume of reservoir restoration and (4) the area of the actual heat exchange. Sanyal SK (Sanyal and Butler, 2005) proposed that the three (3) most substantial statistics that are necessary to evaluate a thermal reservoir's operation are the thermal recovery rate, temperature production, and net power production outlines.

\section{Thermal retrieval runtime}

Though geothermal energy is a renewable energy supply, the average project time period was carried out for 25 years on the base model then 25 years on the optimal and optimized models. The temperature of a fractured reservoir in a geothermal system after thermal retrieval could potentially decline severely and could take approximately 100 years to re-establish. Consequently, it is vital to combine the geothermal energy utilization to preserve viable expansion. Previous investigations have revealed that the optimal time to discontinue thermal retrieval is when the temperature declines by $10{ }^{\circ} \mathrm{C}$ or when the production well temperature has exhausted by $10 \%$.

\section{Optimization technique-hydraulic fracturing}

Hydraulic fracturing is a favourable simulation procedure used in enhanced geothermal systems to upsurge heat production from a geothermal reservoir by increasing reservoir rock permeability. The objective is to construct a simulation model of an unconventional reservoir, Forest Reserve. The area is stimulated by hydraulic fractures is modelled using the Low Fidelity methodology. The construction and circulation of the hydraulic fractures follows the low fidelity methodology proposed by CMG. The low fidelity hydraulic fracturing modelling procedure is based on a guileless model
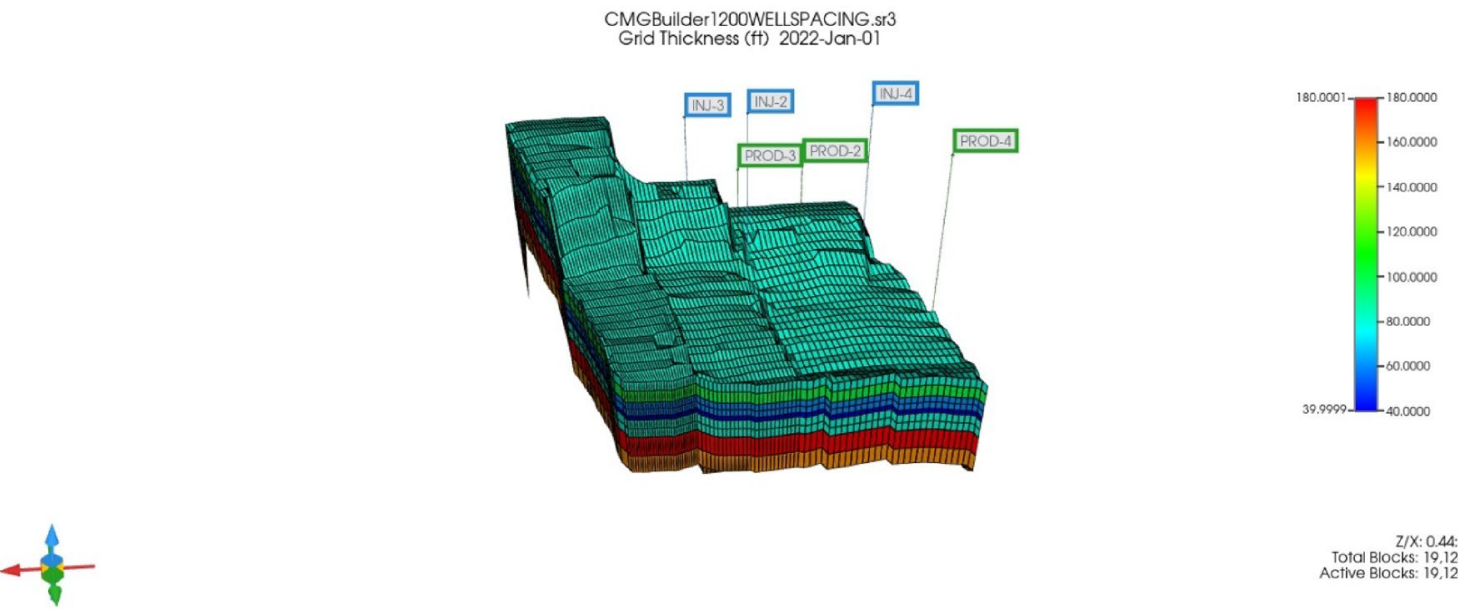

Fig. 5 The geothermal exploitation model (unit: ft.) 
that relays pressure with permeability or transmissibility. It is a basic method to a geomechanical model. It can be used in a single porosity or naturally fractured model, and it allows for the creation of a stimulated reservoir volume (SRV).

\section{Carbon dioxide quantification equation}

There are two main methods for estimating $\mathrm{CO} 2$ emissions from stationary sources, Direct Measurement and Fuel Input Analysis (Agency 2008). Fuel Input Analysis process was chosen for the application in this study and was utilized as described by (Boodlal 2014). The general equation used for the calculation is shown in Eq. 4 describing each component in the formula.

Emissions $=\varepsilon_{i=1}^{n}$ Fuel $_{i} \times \mathrm{HC}_{i} \times \mathrm{C}_{1} \times \mathrm{FO}_{i} \times \frac{\mathrm{CO}_{2(m . w)}}{\mathrm{C}_{(m . w)}}$

Eq. 10Where Fuel $_{i}=$ Mass of Volume of Fuel Type $i$ Combusted, $\mathrm{HC}_{\mathrm{i}}=$ Heat Content of Fuel Type $i$ (Energy/Mass or volume of fuel), $\mathrm{C}_{1}=$ Carbon Content Coefficient of Fuel Type $i$ (Mass C/Energy), $\mathrm{FO}_{i}=$ Fraction Oxidized of Fuel Type $\mathrm{I}, \mathrm{CO}_{2}$ (m.w.) = Molecular weight of $\mathrm{CO}_{2}, \mathrm{C}$ (m.w.) $=$ Molecular Weight of Carbon.

\section{Economic analysis}

Discounted Net Cash Flow (DNCF) is an appraisal technique used to approximate the value of an asset based on its predictable future cash flows (Investopedia 2021). DNCF analysis tries to calculate the worth of an asset today, based on forecasts of future money generation. This applies to the choices of investors in companies or securities, such as acquiring a company, and investing in a technology startup. Below shows the formula used to calculate the DNCF.

Equation to Calculate the DNCF (Investopedia 2021)

Discounted Net Cash flow $($ DNCF $)=$ Net Cash flow $/(1+r)^{n}$

where ' $r$ ' is the minimum acceptable rate of return and ' $n$ ' is the number of years.

\section{Results and discussion}

\section{Analysis of the production of geothermal energy}

The three (3) main parameters that determine the success of the production of geothermal energy are the temperature of the injected working fluid (water), the injection well pressure, and the distance between the injection well and producer wells. Sensitivity simulation analyses were carried out using the initial conditions as can be seen in Tables 1, 2, 3, 4, 5, 6, 7 model to obtain the optimal model for the project.

\section{In terms of the injection stream temperature $\left({ }^{\circ} \mathrm{F}\right)$ sensitivity}

The lifecycle and production performance of a retrofitted abandoned well, or a retrofitted geothermal reservoir, are intensely reliant on the surface temperature of the production well. In a retrofitted geothermal system, the temperature of either the injected or the re-injected fluid heavily reliant on the heat transfer into the reservoir, which results in higher production performance and longer lifetime. It should be noted that the use of too high of an injection temperature can cause damage to the well assembly and bottom hole equipment. Although high-quality metals are used to manufacture the equipment, a high injection temperature over a longer period deteriorates the bottom hole assembly. On the reverse, if the injection temperature is too low, heat flow into the subsurface thermal environment is inadequate to permit the heat flow to attain the preferred quality. Figure 6 shows the evolution of the enthalpy produced utilizing different stream temperatures $\left(77^{\circ} \mathrm{F}, 104^{\circ} \mathrm{F}, 122^{\circ} \mathrm{F}, 140{ }^{\circ} \mathrm{F}\right.$, and $158{ }^{\circ} \mathrm{F}$ ) to evaluate the output temperature with respect to time while keeping other inputs constant as can be seen in the previous Tables 1, 2, 3, 4, 5, 6, 7. It can be seen that each variable increases a linear manner till 2047. The chosen temperature is $140{ }^{\circ} \mathrm{F}$ due to aforementioned points and due to high possibility of utilizing produced water with the approximately the temperature, $140{ }^{\circ} \mathrm{F}$. Having a high initial temperature is vital to the success of the project due the necessary provision of sufficient heat energy to be converted into electrical energy to provide electricity to the designated areas. With that being stated, the type of geothermal plant is highly dependent on the temperature range of the heat being produced from such project. The output temperature was recorded at $210^{\circ} \mathrm{F}$ using an injection temperature of $140{ }^{\circ} \mathrm{F}$.

\section{Injection pressure (psi) sensitivity}

Extremely high injection rates, i.e., higher than a fracture pressure of $1574.5 \mathrm{psi}$, can result in a premature thermal break between the injection and production wells caused by earlier commencement of the convective process in an open loop geothermal system (Hongmei Yin, 2021). Therefore, the injection rate must not be too great unless the intention is to induce fractures within the reservoir. Figure 7 shows the evolution of the enthalpy using different injection pressures (800 psi, $1000 \mathrm{psi}, 1200 \mathrm{psi}$, and $1400 \mathrm{psi}$ ) throughout the 25 -year study period. From the graph, it can be seen that at 1000 psi, 1200 psi, and 1400 psi, the enthalpy increased in a stable linear manner reaching different amounts. The necessary pressure required 


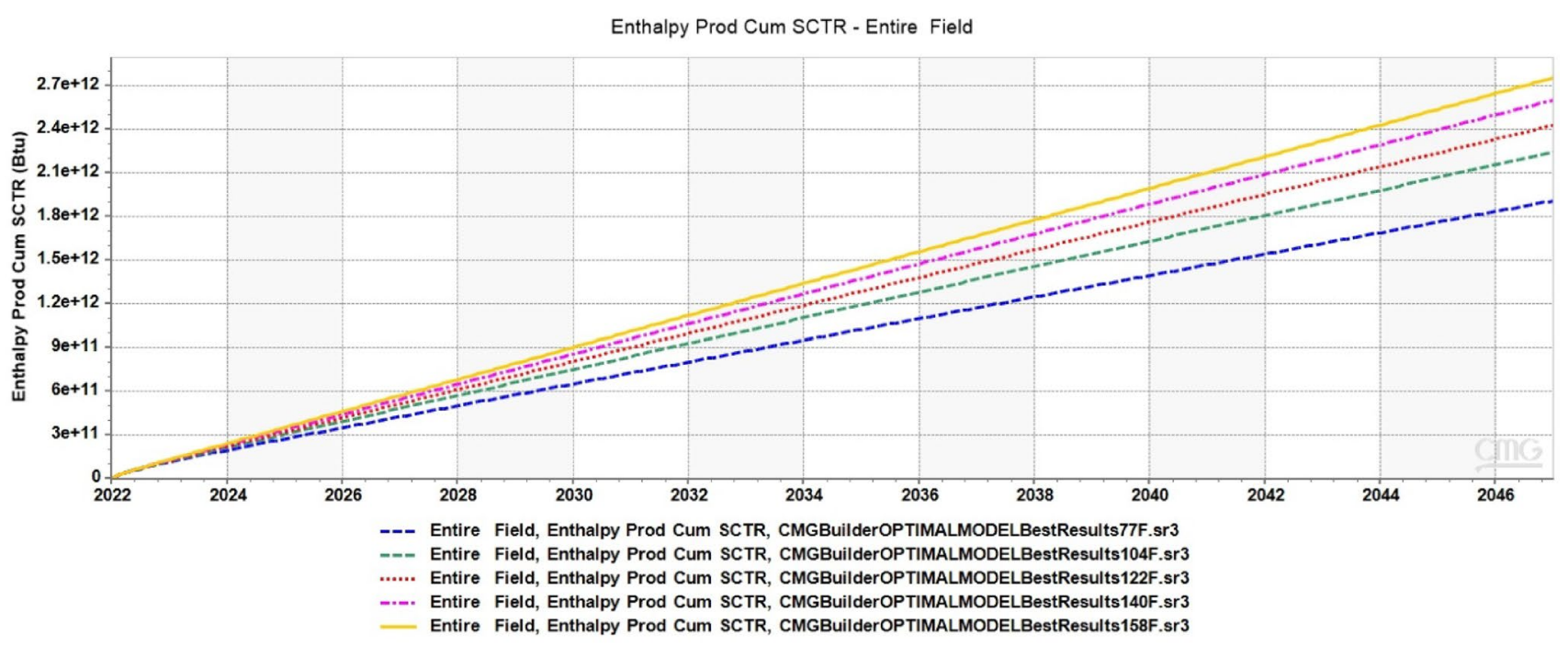

Fig. 6 The evolution of the enthalpy using different stream temperatures throughout the 25-year study period. (Unit: Btu)

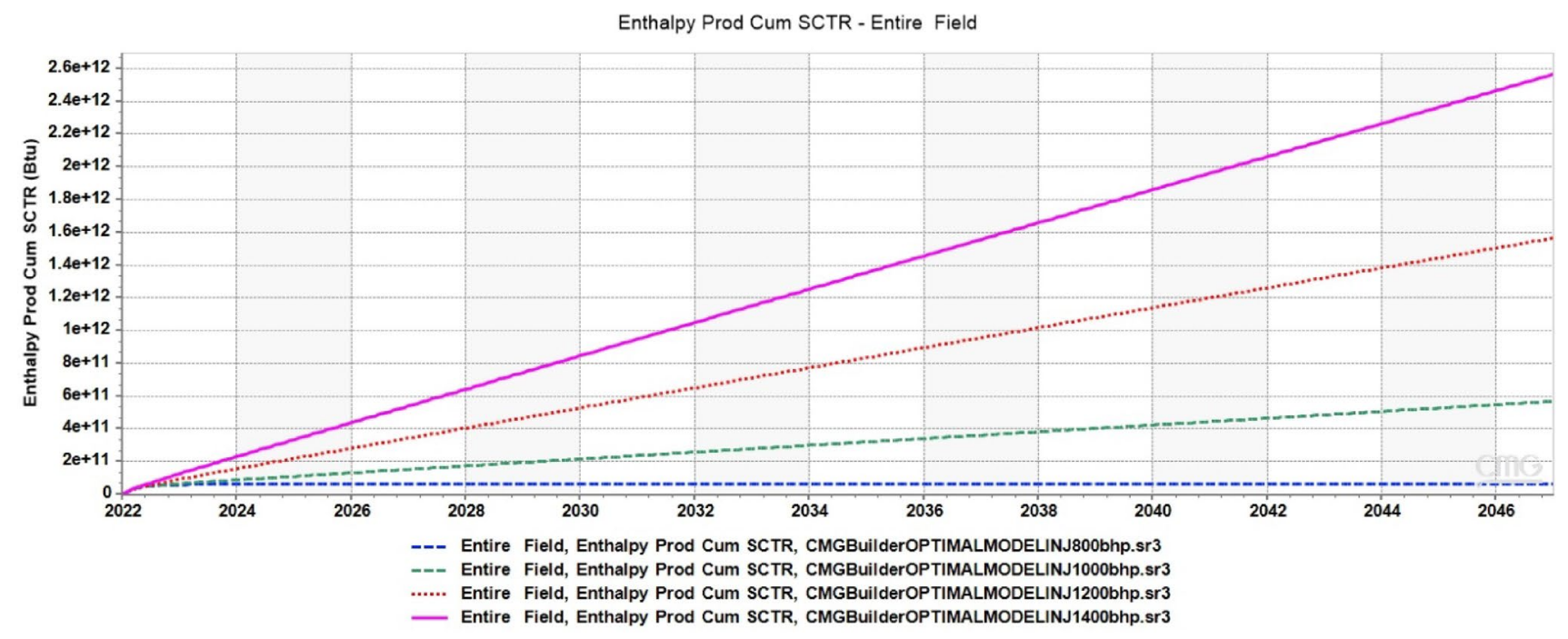

Fig. 7 The evolution of the enthalpy using different injection pressures throughout the 25 -year study period. (Unit: Btu)

to create connective flow with the time allocated for the heat transfer from the reservoir to the water to produce hot water can be the cause of the vast differences seen in Fig. 7. At 800 psi, the enthalpy can be noted as negligible and assumed that the pressure was too low to create the convective process and able to penetrate the reservoir to create a pathflow. An injection pressure of 1400 psi was chosen due the best results produced yet not nearing the fracture pressure (Table 8).

\section{Well spacing sensitivity}

The set time and quantity of heat exchange were significantly subjective by the distance between the injector and producer wells. An appropriate distance between the injection and production wells is essential to evade a thermal breakthrough. If the distance between the injection and production wells is too great, water loss is possible, but the energy exchange between the rocks and fluid will be adequate. An 
Table 8 The $\mathrm{CO}_{2}$ emissions from electricity generation (Administration 2019)

\begin{tabular}{lllll}
\hline Electricity generation & \multicolumn{2}{l}{ CO2 emissions } & Pounds per kWh \\
\cline { 2 - 4 } & million kWh & $\begin{array}{l}\text { million metric } \\
\text { tons }\end{array}$ & million short tons & \\
\hline Coal & $1,124,638$ & 1,127 & 1,240 & 2.21 \\
Natural gas & $1,246,847$ & 523 & 575 & 0.92 \\
Petroleum & 21,860 & 21 & 23 & 2.11 \\
\hline
\end{tabular}

injection well too nearby to the production well will result to a premature thermal development, as a result of a lower flux of heat between the rocks and the fluid (Jung, 2012). Therefore, the distance between the injection and production wells plays a critical part in the working lifespan and performance of the system. Figure 8 shows the evolution of the enthalpy using different well spacings $(1200 \mathrm{ft}, 1400 \mathrm{ft}, 1600 \mathrm{ft}$, and $1800 \mathrm{ft}$ ) throughout the 25 -year study period. Each variable showed a constant stable linear increase in Fig. 8. Note that the differences are minuscule due the distances being not of a great variance. The well distance of $1600 \mathrm{ft}$ was chosen due it being the furthest from each other without stepping out of the set boundary of the field.

\section{Optimal model design (retrofitted geothermal system)}

Based on the sensitivity analyses conducted earlier, an injection temperature of $140^{\circ} \mathrm{F}$, an injection pressure of 1400 psi, and a well spacing of $1600 \mathrm{ft}$ were utilized to design the optimal model for application at the Forest Reserve, Trinidad. From Fig. 9, it can be seen that the enthalpy produced in a constant stable linear manner to approximately $2.9 \mathrm{E}+12$ Btu. It should be noted that by utilizing the sensitivity analysis process, the optimal model shown, in Fig. 9, produced the highest enthalpy when compared to Fig. 6, 7 and 8 thus demonstrating the importance of the each sensitivity variable.

The total production of energy prominently relies on the surface production temperature that exemplifies the output temperature connection with the energy harnessed out of the system. In Fig. 9 the operation can be seen to be acting in a steady increasing phase throughout the twenty-five (25) year period and peaked at $2.9 \mathrm{E}+12 \mathrm{Btu}$. This pattern demonstrates that the retrofitted geothermal system can be successful for the full twenty-five (25) years for thermal recovery runtimes and provide another form of harnessing electricity.

\section{Hydraulic fracturing with injection pressure sensitivities}

Hydraulic fracturing was applied to the optimal model design obtained to enhance heat recovery. This was done by utilizing a Form Factor (ff) of 2500 and alternating the surface water rate (bbl/day) then stopping, equating to zero (0) bbl/day using cold water to induce permanent fractures in the formation during the first fifteen (15) days of production shutting in the well. An injection pressure

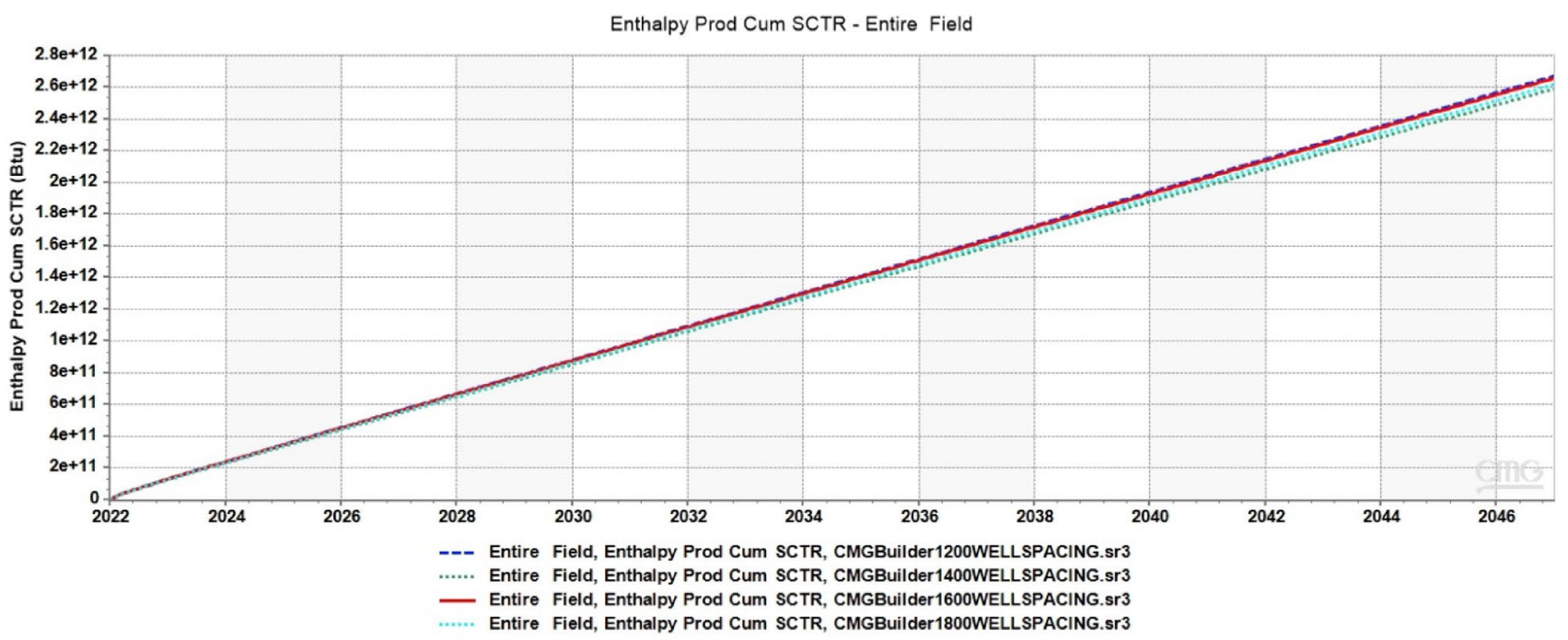

Fig. 8 The evolution of the enthalpy using different well spacings throughout the 25-year study period. (Unit: Btu) 


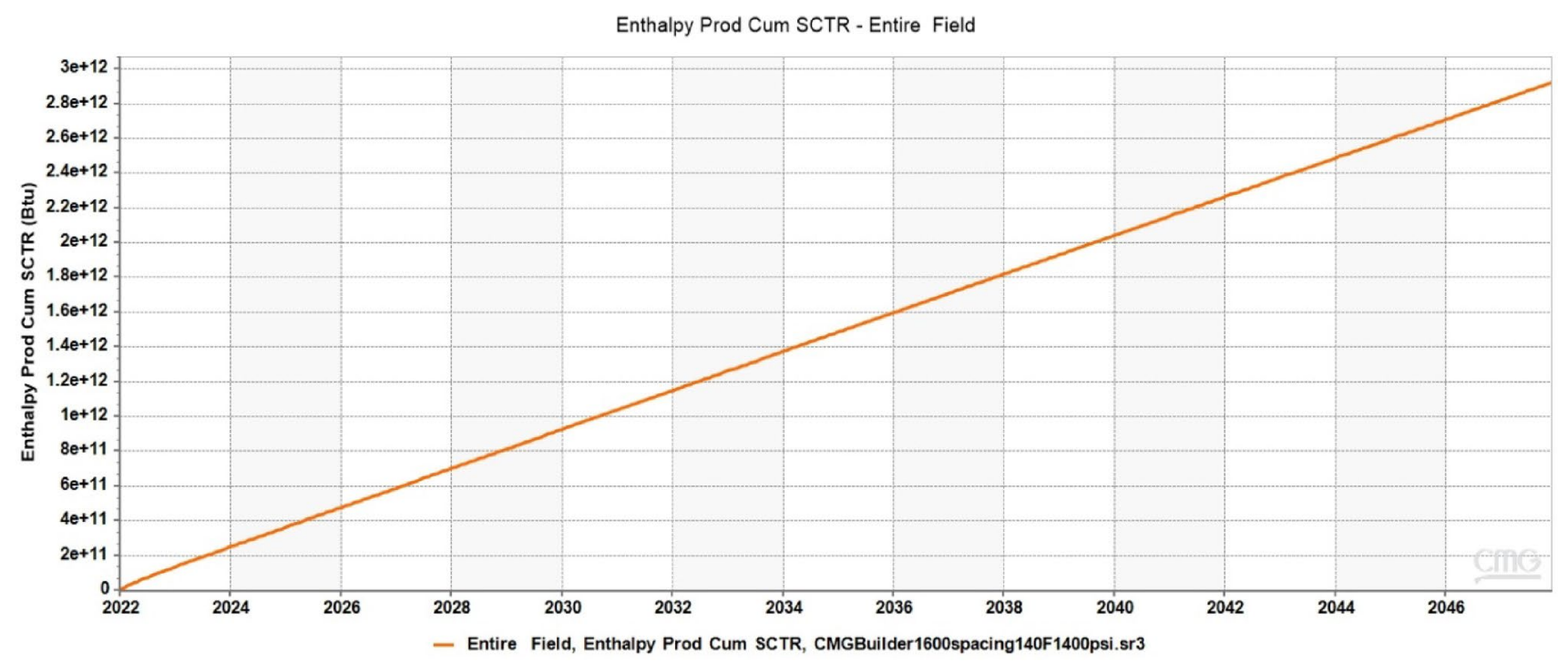

Fig. 9 The evolution of the enthalpy throughout the 25-year study period. (Unit: Btu)

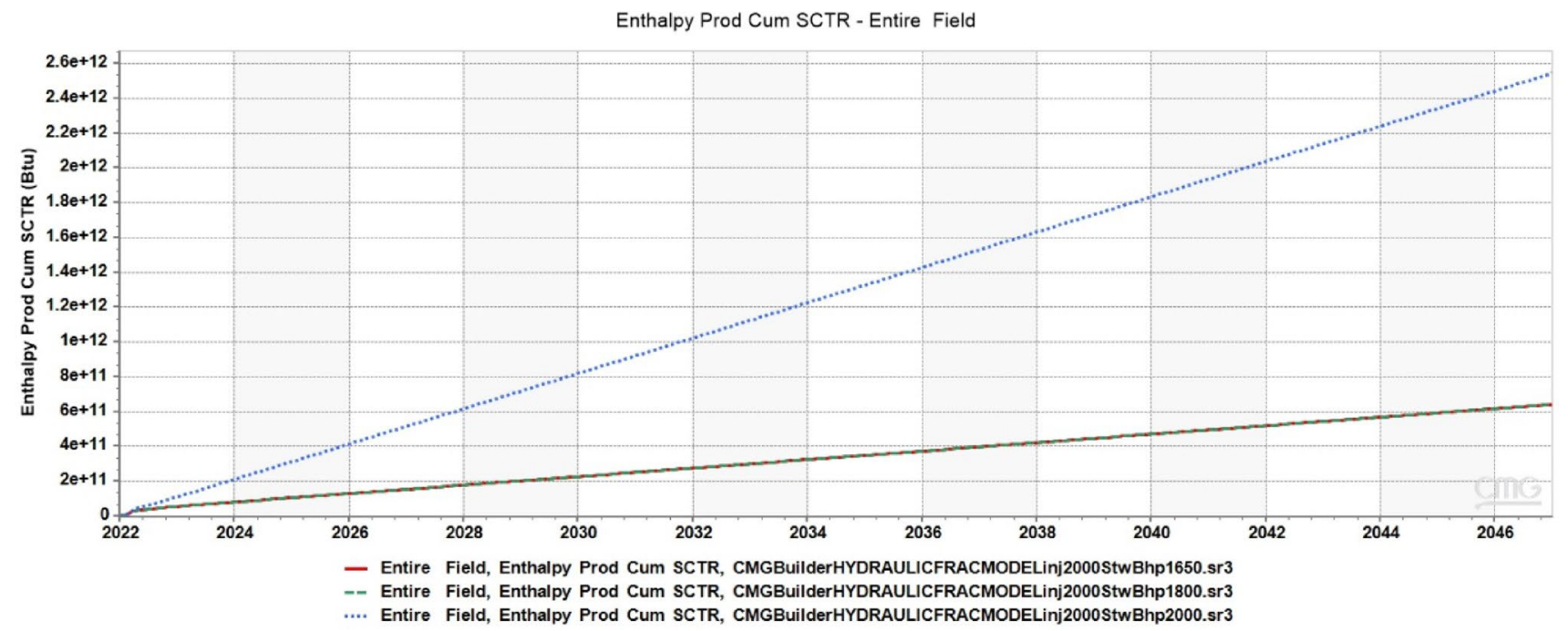

Fig. 10 The evolution of the enthalpy using different hydraulic fracturing pressures throughout the 25-year study period. (Unit: Btu)

was calculated using the reference depth of $2250 \mathrm{ft}$ multiplied by an estimated fracture gradient of $0.7 \mathrm{psi} / \mathrm{ft}$ resulting in 1574.5 psi. Thereafter, injection pressures higher than the fracture pressure of 1574.5 psi were utilized. Figure 10 shows the corresponding enthalpy production using different hydraulic fracturing pressures (1650 psi, 1800 psi, and $2000 \mathrm{psi}$ ) throughout the 25 -year study period. It can be seen that even though 1650 psi and 1800 psi are greater than the fracture pressure of $1574.5 \mathrm{psi}$, they both produced quite lower than at $2000 \mathrm{psi}$. This could be assumed as the pressure only fractured around the injection wellbore and not further into the reservoir. Also this is exposes the fracture gradient can be of a higher value and not estimated at $0.7 \mathrm{psi} / \mathrm{ft}$. This theory could be proven in a leak-off test but was not done performed. Therefore the pressure of 2000 psi was chosen to move forward as it showed significant results.

\section{Comparison of optimal EGS model to optimized EGS model, 25-year lifecycle}

Figure 11 shows the comparison of the optimal model and the optimized (hydraulic fracturing) model evolution of the enthalpy produced throughout a 25 -year period. It shows a lower enthalpy in the hydraulic fracturing model when 


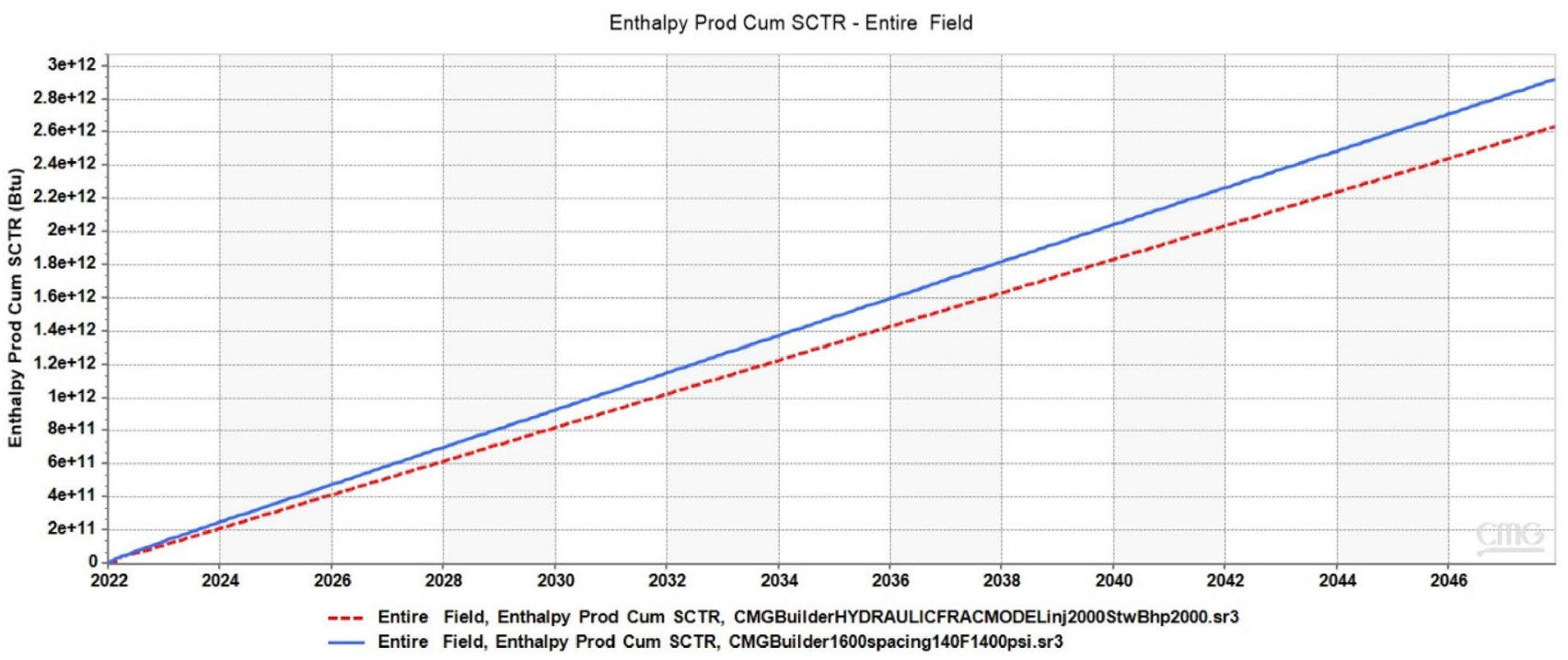

Fig. 11 The comparison of the optimal EGS model to optimized EGS model evolution of the enthalpy throughout the 25-year study period. (Unit: Btu)

compared to the optimal model. Both models produced in a steady state till 2047. The purpose of Fig. 11 is to decide the best model/procedure appropriate for the reservoir to produce the superlative results. Unfortunately, due to the shallow nature of the field at present, hydraulic fracturing would not be recommended due to depth, possible the loss of water into the formation, more water being force into the reservoir resulting in less time for the heat transfer to occur, and the possibility of the induced fracture not travelling in the desired direction due to the reservoir type being sandstone.

Figure 12 demonstrates the comparison of the optimal model and the optimized model's average formation temperature over a 25 -year period. It shows the optimal model producing a lower formation temperature at 205.3 ${ }^{\circ} \mathrm{F}$ at the end of the 25-year period when compared to the optimized retrofitted system that resulted to $206.1^{\circ} \mathrm{F}$. Both models demonstrated a linear decline. This linearity is due to the constant heat supply due to the system's stable temperature (i.e., it remained within the maximum and minimum values). An almost instantaneous dip in temperature can be seen in the optimized model when the hydraulic fracturing was implemented for the first 15 days then the temperature increased back the 'standard' level in the generated graph.

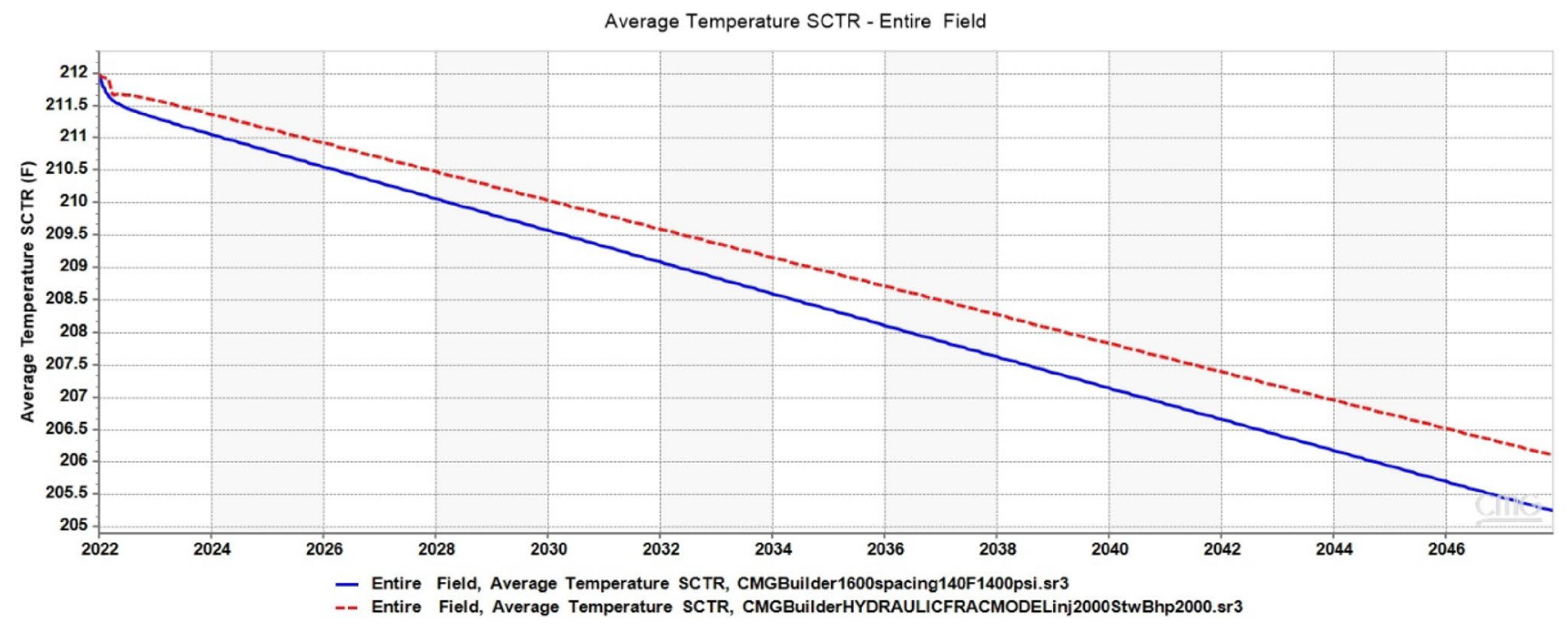

Fig. 12 The evolution of the comparison of the optimal EGS model to the optimized EGS model average formation temperature throughout a 25-year period. (Unit: ${ }^{\circ} \mathrm{F}$ ) 
From the data produced the recommendation would be to implement the optimal retrofitted system.

\section{Size and type of applicable plant}

Below shows the calculation done to calculate the production capacity of the plant. The calculation utilizes the peaked cumulative enthalpy produced from the optimal model to generate the potential baseload electricity, Watts per second.

1. Peaked Enthalpy Cumulative after 25 years, $\mathrm{Btu}=2.8 \mathrm{E}+12 \mathrm{Btu}$

2. Enthalpy Btu converted to Enthalpy, Joules $=2.8 \mathrm{E}+12$ $\times 1055=2.954 \mathrm{E}+15 \mathrm{~J}$

3. Joules converted to Mega Joules $=2.954 \mathrm{E}+15 / 1 \mathrm{E}+6$ $\mathrm{MJ}=2.954 \mathrm{E}+09 \mathrm{MJ}$

4. Plant Life, 25 years to seconds $=25 \times 365 \times 24 \times 3600=788,400,000 \mathrm{~s}$

5. Plant Capacity $=90 \%$

6. Joules converted to Joules per seconds $=2.954 \mathrm{E}+15 / 788,400,000=3,746,829.021$

7. Joules $/$ second $=$ Watts $/$ second $=3,746,829.021 \mathrm{~W} / \mathrm{s}$

8. Watts per second converted plant size $=3,746,829.021$ $\times 0.9=3,372,146.119 \mathrm{~W} / \mathrm{s}$ $=3.3721 \mathrm{MWe}$

Given that the reservoir temperature is approximately $212^{\circ} \mathrm{F}$, the appropriate and applicable plant type to Trinidad's context would be the installation of a Binary Open Loop Cycle Plant with the addition of a separation tank. A separation tank is required in the installation aspect of the project due to the possibility of producing hot water with oil that could potentially cause damage to the heat exchanger. Using the size of the plant calculation, the binary open-loop cycle plant has the potential to be in operation for 25 years providing 3.3721 MWe of baseload power which possess the potential to supply constant electricity to approximately 2200 houses within the district of the proposed plant. Though the capacity of the plant seems small, the feasibility of the project is explored in the economic evaluation. There are a few small geothermal plants that exists worldwide such as Guadeloupe (4.5 MW), Taiwan (0.3 MW), Thailand (0.3 MW), Austria (1.2 MW), Australia (1.7 MW), Hungary (3 MW), Belgium (0.8 MW) and Ethiopia (7.3 MW) (Huttrer 2020).

This type of operation can potentially result in a breakthrough for TT and the Caribbean as it will be the first retrofitted geothermal system to be launched in the region. This project can also reveal new employment opportunities and comply with the agreement as was signed from the Government of TT in 2018 (Government Ratifies Paris Agreement 2018). The power plant would require a turbine, generator, a cooling tower, the 3 injection wells, the 3 production wells and a Separation tank. A rough estimate of plant size would require 1-8 acres per MW, therefore using the highest case scenario of 8 acres per MW would result in approximately 26.496 acres.

\section{Carbon dioxide emission reduction}

Referencing Table 8, the $\mathrm{CO}_{2}$ emission rate produced from natural gas is approximately $0.92 \mathrm{lbs} / \mathrm{kWh}$ (Administration 2019) while a Binary Open-Loop Cycle Plant emits $0.1 \mathrm{lbs} / \mathrm{kWh}$ (Scientist 2013). Figure 13 was constructed to demonstrate the average annual carbon dioxide emission reduction that can be generated from the implementation of the Binary Open-Loop Cycle Plant for a 25-year lifecycle of the proposed plant lifecycle (highlighted in red). This was done using the annual cumulative enthalpy production, $\mathrm{Btu}$, converted into $\mathrm{kWh}$ to provide the annual total heat production of the optimal model. $1 \mathrm{Btu}$ is equal to approximately $0.000293071 \mathrm{kWH}$ (Bureau International des Poids et Mesures 2019). The enthalpy production was then multiplied by the respective factors, $\mathrm{CO}_{2}$ emissions produced from a binary plant $(0.1 \mathrm{lbs} / \mathrm{kWh})$, and from natural gas generated electricity $(0.92 \mathrm{lbs} / \mathrm{kWh})$. The Difference between the Binary Open-Loop and Natural Gas carbon dioxide emission revealed the approximate reduction in $\mathrm{CO}_{2}$ gas being emitting from the generation of electric energy. The idea is to estimate the amount of $\mathrm{CO}_{2}$ emissions produced from replacing the natural gas generated electricity with geothermal energy (a cleaner, and renewable energy source) to obtain the reduction of $\mathrm{CO}_{2}$ emissions. The Cumulative annual carbon dioxide reduction was estimated to be approximately $1.00125 \mathrm{E}+11 \mathrm{lbs}$ which is equivalent to $50,062,500$ tons of carbon dioxide after a 25 -year period. An approximate $88.9 \%$ reduction of $\mathrm{CO}_{2}$ from replacing $3.3721 \mathrm{MW}$ of natural gas generated electricity with $3.3721 \mathrm{MW}$ of enhanced geothermal electricity. This reduction in $\mathrm{CO}_{2}$ will result in a cleaner and renewable way of producing electricity not affected by meteorological conditions, therefore reducing the country's carbon footprint.

\section{Economic analysis}

Geothermal energy is often misinterpreted to be an expensive source of electricity. Though it may be true, geothermal power plants require a substantial amount of initial capital and some government assistance in the early stages. The overall and operating costs of geothermal power are significantly lower than other technologies (Gawell 2014). The geothermal power plant has no fuel costs and minimal maintenance or ancillary costs. Once the plant begins operations, it can generate electricity for 30 years or longer given if

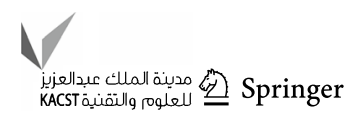


Table 9 The parameters used in the economic analysis

\begin{tabular}{|c|c|c|c|c|}
\hline Year & Production kWh & Price & OPEX US\$ & CAPEX US\$ \\
\hline 2022 & - & 0.05 & - & $12,000,000$ \\
\hline 2023 & $295,650,688$ & 0.05 & $2,000,000$ & - \\
\hline 2024 & $662,685,209$ & 0.05 & $2,000,000$ & - \\
\hline 2025 & $1,064,082,025$ & 0.05 & $2,000,000$ & - \\
\hline 2026 & $1,462,026,835$ & 0.05 & $2,000,000$ & - \\
\hline 2027 & $1,858,587,448$ & 0.05 & $2,000,000$ & - \\
\hline 2028 & $2,254,355,961$ & 0.05 & $2,000,000$ & - \\
\hline 2029 & $2,650,411,253$ & 0.05 & $2,000,000$ & - \\
\hline 2030 & $3,045,228,102$ & 0.05 & $2,000,000$ & - \\
\hline 2031 & $3,439,413,390$ & 0.05 & $2,000,000$ & - \\
\hline 2032 & $3,833,195,627$ & 0.05 & $2,000,000$ & - \\
\hline 2033 & $4,227,510,277$ & 0.05 & $2,000,000$ & - \\
\hline 2034 & $4,620,770,646$ & 0.05 & $2,000,000$ & - \\
\hline 2035 & $5,013,541,493$ & 0.05 & $2,000,000$ & - \\
\hline 2036 & $5,406,023,574$ & 0.05 & $2,000,000$ & - \\
\hline 2037 & $5,799,130,168$ & 0.05 & $2,000,000$ & - \\
\hline 2038 & $6,191,264,748$ & 0.05 & $2,000,000$ & - \\
\hline 2039 & $6,582,978,337$ & 0.05 & $2,000,000$ & - \\
\hline 2040 & $6,974,460,514$ & 0.05 & $2,000,000$ & - \\
\hline 2041 & $7,366,612,457$ & 0.05 & $2,000,000$ & - \\
\hline 2042 & 7,757,831,913 & 0.05 & $2,000,000$ & - \\
\hline 2043 & $8,148,660,113.57$ & 0.05 & $2,000,000$ & - \\
\hline 2044 & $8,539,277,876.23$ & 0.05 & $2,000,000$ & - \\
\hline 2045 & $8,930,577,044.26$ & 0.05 & $2,000,000$ & - \\
\hline 2046 & $9,320,952,177.73$ & 0.05 & $2,000,000$ & - \\
\hline 2047 & $9,710,935,478.19$ & 0.05 & $2,000,000$ & - \\
\hline
\end{tabular}

the field is engineered and maintained sustainably (Gawell 2014).

Table 9 shows the production of Kwh per year for a 25-year period with the cost of geothermal electricity, US\$ and its corresponding CAPEX, Capital Expenditure and OPEX, Operating Expenditure. Due to the nature of this project, CAPEX reduced by approximately $50 \%$. The approximate cost of setting up a geothermal plant is roughly US \$2-\$7 MM per Megawatt. Using this information, the highest case scenario of US\$7MM was chosen. That figure was then multiplied by $3.3721 \mathrm{MW}$ totalling the cost to US\$23.6MM. Now, this US\$23.6MM was divided half and rounded off to give \$12MM US.

Well workovers are required to retrofit these wells to harness the geothermal energy. The cost of setting up a small Binary Cycle plant with a separation tank is also included. The OPEX is approximated to cover maintenance, repairs, and salaries for the employees. A simple economic analysis using appropriate assumptions was carried out. Utilizing Crystal Ball, Monte Carlo sensitivities were done to show the feasibility of the project (Fig. 13).

Table 10 demonstrates the cash flows for the project. Cash inflows are calculated using the production multiplied by the price and the Cash Outflows are calculated by the addition of CAPEX and OPEX. The Net Cash flow is the difference between the Inflow and Outflow leaving the remainder. The Remainder is the monetary value the project is generating, USD $\$ 6,195,808,168$ for the 25-year period, highlighted in yellow.

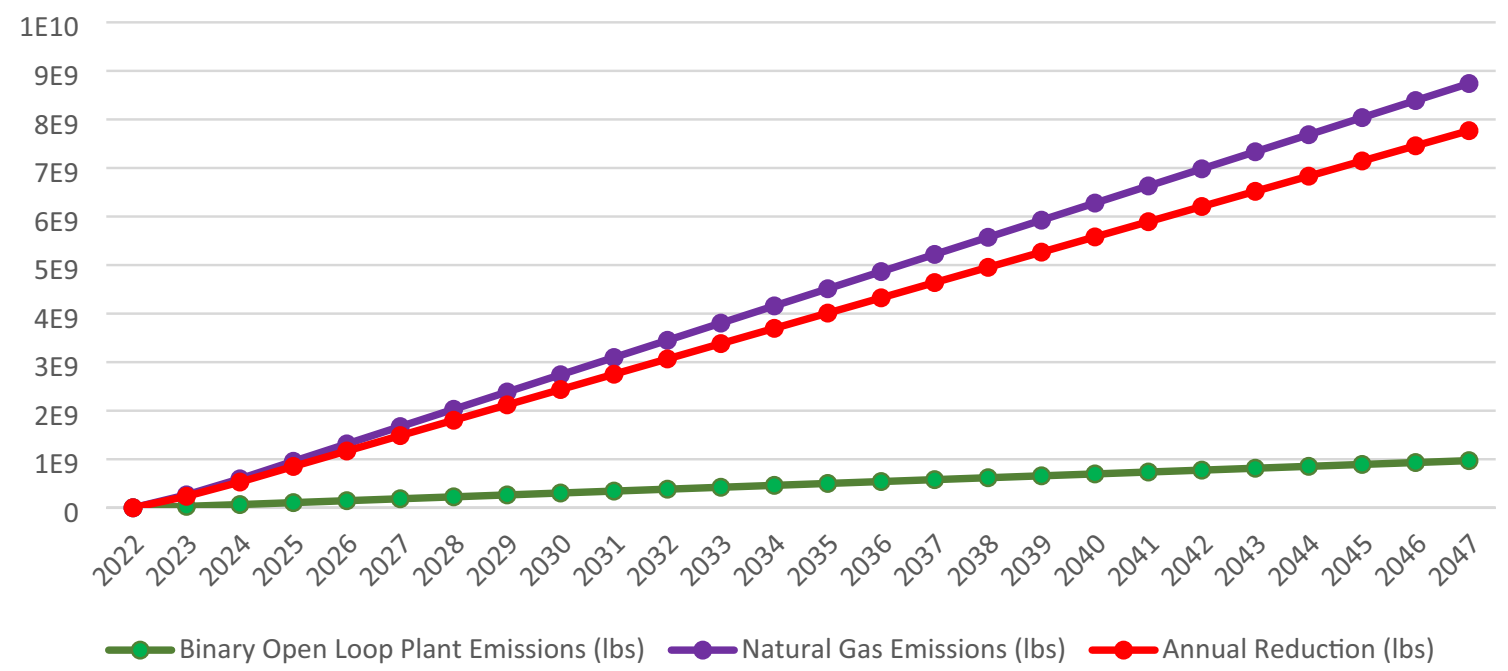

Fig. 13 Cumulative carbon dioxide emission reduction from the difference in the optimal model and natural gas generated electricity 
Table 10 Cash flows for the proposed project

\begin{tabular}{|c|c|c|c|}
\hline Year & Cash inflow US\$ & Cash outflow US\$ & Net cashflow US\$ \\
\hline 2022 & - & $12,000,000$ & $-12,000,000$ \\
\hline 2023 & $14,782,534$ & $2,000,000$ & $12,782,534$ \\
\hline 2024 & $33,134,260$ & $2,000,000$ & $31,134,260$ \\
\hline 2025 & $53,204,101$ & $2,000,000$ & $51,204,101$ \\
\hline 2026 & $73,101,342$ & $2,000,000$ & $71,101,342$ \\
\hline 2027 & $92,929,372$ & $2,000,000$ & $90,929,372$ \\
\hline 2028 & $112,717,798$ & $2,000,000$ & $110,717,798$ \\
\hline 2029 & $132,520,563$ & $2,000,000$ & $130,520,563$ \\
\hline 2030 & $152,261,405$ & $2,000,000$ & $150,261,405$ \\
\hline 2031 & $171,970,669$ & $2,000,000$ & $169,970,669$ \\
\hline 2032 & $191,659,781$ & $2,000,000$ & $189,659,781$ \\
\hline 2033 & $211,375,514$ & $2,000,000$ & $209,375,514$ \\
\hline 2034 & $231,038,532$ & $2,000,000$ & $229,038,532$ \\
\hline 2035 & $250,677,075$ & $2,000,000$ & $248,667,075$ \\
\hline 2036 & $270,301,179$ & $2,000,000$ & $268,301,179$ \\
\hline 2037 & $289,956,508$ & $2,000,000$ & $287,956,508$ \\
\hline 2038 & $309,563,237$ & $2,000,000$ & $307,563,237$ \\
\hline 2039 & $329,148,917$ & $2,000,000$ & $327,148,917$ \\
\hline 2040 & $348,723,026$ & $2,000,000$ & $346,723,026$ \\
\hline 2041 & $368,330,623$ & $2,000,000$ & $366,330,623$ \\
\hline 2042 & $387,891,596$ & $2,000,000$ & $385,891,596$ \\
\hline 2043 & $407,433,006$ & $2,000,000$ & $405,433,006$ \\
\hline 2044 & $426,963,894$ & $2,000,000$ & $424,963,894$ \\
\hline 2045 & $446,528,852$ & $2,000,000$ & $444,528,852$ \\
\hline 2046 & $466,047,609$ & $2,000,000$ & $464,047,609$ \\
\hline \multirow[t]{2}{*}{2047} & $485,546,774$ & $2,000,000$ & $483,546,774$ \\
\hline & $6,257,808,168$ & $62,000,000$ & $6,195,808,168$ \\
\hline
\end{tabular}

Table 11 The IRR and payback period

\begin{tabular}{ll}
\hline IRR & $190 \%$ \\
\hline PAYBACK & 2024 \\
& 11.27 \\
& January \\
\hline
\end{tabular}

Table 11 shows the Internal Rate of Return of $190 \%$ and the payback period in January, 2024 highlighted in yellow once production starts in January, 2023. A positive IRR indicates that the project is indeed feasible. IRR is calculated by taking the difference between the current or expected future value and the original beginning value, divided by the original value and multiplied by 100 (Investopedia 2021). The payback period is equal to Initial investment divided by Cash flow per year (Investopedia 2021).

Utilizing a Minimum Rate of Return of $10 \%$, means the company is willing to accept a minimum of $10 \%$ of the return which summed up to US\$1,431,263,840.00 which can be seen in Table 12. A positive NPV, Net Present
Table 12 The DNCF and Interest using 10\% MARR

\begin{tabular}{|c|c|c|}
\hline $\begin{array}{l}\text { Number of } \\
\text { years }\end{array}$ & $\begin{array}{l}\text { Discounted net cashflow } \\
\text { using 10\% MARR US\$ }\end{array}$ & Interest using $10 \%$ MARR \\
\hline 0 & $-12,000,000$ & - \\
\hline 1 & $11,620,486$ & $1,612,049$ \\
\hline 2 & $25,730,794$ & $5,403,467$ \\
\hline 3 & $38,470,399$ & $12,733,702$ \\
\hline 4 & $48,563,173$ & $22,538,169$ \\
\hline 5 & $56,459,986$ & $34,469,386$ \\
\hline 6 & $62,497,311$ & $48,220,487$ \\
\hline 7 & $66,977,686$ & $63,542,876$ \\
\hline 8 & $70,098,054$ & $80,163,351$ \\
\hline 9 & $72,084,156$ & $97,886,513$ \\
\hline 10 & $73,122,056$ & $116,537,725$ \\
\hline 11 & $73,384,840$ & $135,990,674$ \\
\hline 12 & $72,978,735$ & $156,059,797$ \\
\hline 13 & $72,032,891$ & $176,644,184$ \\
\hline 14 & $70,652,086$ & $197,649,093$ \\
\hline 15 & $68,934,499$ & $219,022,010$ \\
\hline 16 & $66,934,722$ & $240,628,516$ \\
\hline 17 & $64,724,699$ & $262,424,248$ \\
\hline 18 & $62,361,184$ & $284,361,842$ \\
\hline 19 & $59,897,984$ & $306,432,639$ \\
\hline 20 & $57,360,327$ & $328,531,269$ \\
\hline 21 & $54,786,394$ & $350,646,612$ \\
\hline 22 & $52,205,103$ & $372,758,791$ \\
\hline 23 & $49,644,163$ & $394,884,689$ \\
\hline 24 & $47,112,711$ & $416,934,898$ \\
\hline \multirow[t]{2}{*}{25} & $44,629,432$ & $438,917,342$ \\
\hline & $1,431,263,840$ & $4,764,544,327$ \\
\hline
\end{tabular}

Value, implies that the investment is generating a rate of return which is greater than the MARR of $10 \%$. Utilizing Crystal Ball, Monte Carlo simulations were done to obtain the feasibility of the project. The assumption variables are (1) Price, US\$0.05-0.10 per kWh, with US $\$ 0.05$ per $\mathrm{kWh}$ being the likeliest (2) CAPEX, US\$10-14MM with US\$12MM being the likeliest, and (3) OPEX, US\$1$3 \mathrm{MM}$ with US\$2MM being the likeliest. The defined forecast used an excel generated IRR of $190 \%$ and NPV of US $\$ 1,431,263,840$. The IRR forecast revealed that it has a $100 \%$ certainty of obtaining higher than a MARR of $10 \%$ showing that the project again is indeed feasible.

\section{Conclusion}

A generic model was constructed using actual and adopted geological parameters and data using three (3) injector and three (3) producer wells with a recorded temperature of 212 ${ }^{\circ} \mathrm{F}$ for a 25 -year time period. The optimal model resulted in

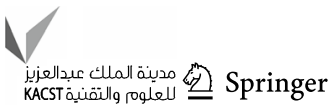


a maximum enthalpy cumulative value of $2.8 \mathrm{E}+12 \mathrm{Btu}$ for a time period of 25 years. Hydraulic fracturing of the optimal model was conducted and the results revealed the optimum injection pressure should be 2000 psi to provide a maximum enthalpy cumulative value of $2.6 \mathrm{E}+12 \mathrm{Btu}$. It was demonstrated that the optimal model, produced a slightly higher enthalpy of $0.2 \mathrm{E}+12 \mathrm{Btu}$. The plant capacity was calculated to be $3.3721 \mathrm{MW}$ using a binary open-loop cycle requiring a land space of approximately 26.496 acres. Using the cumulative enthalpy production, the carbon dioxide average reduction of 50,062,500 tons of $\mathrm{CO}_{2}$ after the 25-year period. An economic analysis of the project found an IRR of $190 \%$ and an NPV of US $\$ 1,431,263,840.00$ utilizing a MARR of $10 \%$, CAPEX of US \$12MM, OPEX of US\$2MM and a cost of geothermal electricity at US $\$ 0.05$ per $\mathrm{kWh}$. These results were then used in Crystal Ball to apply Monte Carlo simulations where it confirms that the project is $100 \%$ economically feasible.

Funding This statement confirms that this study received no specific grant or funding from any agency.

\section{Declarations}

Conflict of interest On behalf of all the co-authors, the corresponding author states that there is no conflict of interest. The research was conducted with Compliance with Ethical Standards and did not involve Human Participants and/or Animals.

Open Access This article is licensed under a Creative Commons Attribution 4.0 International License, which permits use, sharing, adaptation, distribution and reproduction in any medium or format, as long as you give appropriate credit to the original author(s) and the source, provide a link to the Creative Commons licence, and indicate if changes were made. The images or other third party material in this article are included in the article's Creative Commons licence, unless indicated otherwise in a credit line to the material. If material is not included in the article's Creative Commons licence and your intended use is not permitted by statutory regulation or exceeds the permitted use, you will need to obtain permission directly from the copyright holder. To view a copy of this licence, visit http://creativecommons.org/licenses/by/4.0/.

\section{References}

Administration, U. E. (2019). How much carbon dioxide is produced per kilowatthour electricity generation?

Agency, U. S. (2008). Climate leaders greenhouse gas inventory protocol core module guidance: direct emissions from stationary combustion sources.

American Geosciences Institute. (2020). What is an enhanced geothermal system? Retrieved from Frequently asked questions, explore the geosciences: www.americangeosciences.org/critical-issues/ faq/enhanced-geothermal-system\#: :text

Bu XM (2012) Geothermal energy production utilising abandoned oil and gas wells. Renew Energy 41:80-85
Bureau International des Poids et Mesures (2019) The international system of units (SI), 9th edition.

Caulk RT (2009) Reuse of abandoned oil and gas wells for geothermal energy production. University of California, San Diego

Caulk RT (2017) Reuse of abandoned wells for geothermal energy extraction and utilization in oilfields. Renew Energy 112:388-397

Chamber E (2021) Time to end the natural gas subsidy to the T\&T electricity sector.

Davis AM (2009) Geothermal power production from abandonedoil wells. Energy 34(7):866-872

Donnie Boodlal DA (2014) The use of reservoir simulation to obtain key parameters for investigating the feasibility of implementing flue gas CO2-EOR coupled with sequestration in Trinidad. Energy Proced 63:7517-7528

Energy Snapshot (2015) Energy Snapshot-Trinidad and Tobago (Fact Sheet). Retrieved from Energy transition initiative-islands: https:// www.cia.gov/library/publications/the-world-factbook/geos/td. html

Evans (2010) An introduction with overviews of deep systems built and circulated to date. Beijing: Enhanced/engineered Geothermal System.

Gawell BM (2014) Economic costs and benefits of geothermal power. Geotherm Energy Assoc, 3.

Government of Trinidad \& Tobago. (2015). Vision 2030. Port of Spain: Government of Trinidad and Tobago Printery.

(2018). Government ratifies paris agreement. United Nations Development Programme.

Govinda Hosien PH (2020) Predicting renewable energy investment using machine learning. Energies 13:4494

Hongmei Yin CS (2021) Analysis of flow and thermal breakthrough in leaky downhole coaxial open loop geothermal system. Appl Therm Eng 194:117098

Huttrer GW (2020) Geothermal power generation in the World 2015-2020 Update Report. Iceland: World Geothermal Congress 2020.

Indar D (2019) National energy efficiency monitoring report of trinidad and tobago. United Nations publication, Santiago

Investopedia JF (2021) Discounted cash flow (DCF).

Jung Y (2012) Water resources search. A closed-form analytical solution for thermal single-well injection-withdrawal tests.

Liang B, Jiang H, Li J, Gong C (2016) A systematic study of fracture parameters effect on fracture network permeability based on discrete-fracture model employing finite element analyses. J Nat Gas Sci Eng 28:711-722

Macenic MK (2017) Revitalisation of abandoned oil and gas wells for a geothermal heatexploitation by means of closed circulation: case study of the deep dry well Pcelic-1. Interpretation 6:SB1-SB9

Marzolf N (2015) A unique approach to sustainable energy in trinidad and tobago. Port of Spain: Inter American Development Bank (IADB).

Nian YC (2018) Evaluation of geothermal heatingfrom abandoned oil wells. Energy 142:592-607

Now (2020) Trinidad \& Tobago oil production hits lowest since 1950's. Oil Now.

Sanyal SK, \& Butler SJ (2005) An analysis of power generation prospects from enhanced geothermal systems. Antalya: World Geothermal Congress.

Scientist UO (2013) Environmental impacts of geothermal energy. Office of Energy Efficiency \& Renewable Energy.

Sliwa TR (2014) Use of boreholes in the Carpathians in geoenergetics systems historical and conceptual review. Res J Environ Sci $8(5): 231-242$

Sun Z-X et al (2017) Numerical simulation of the heat extraction in EGS with thermal-hydraulic-mechanical coupling method based on discrete fractures model. Energy 120:20-33 
Templeton JD (2014) Abandoned petroleum wells as sources of geothermal energy. Energy 70:366-373

Tester JC (1994) Prospects for universal geothermal energy from heat mining. Sci Glob Secur 5(1):99-121

Trinity (2021) Forest reserve oil trend. Retrieved from Trinity Exploration and Production Company: http://www.trinityexploration.com/ our-assets/onshore/

W C (1983). Hydraulics (Second Edition). Beijing: Higher Education Press

Worldmeter (2021) Trinidad and Tobago Oil. Retrieved from

Xu C, Dowd PA, Tian ZF (2015) A simplified coupled hydro-thermal model for enhanced geothermal systems. Appl Energy 140:135-145

Yao JM (2019) Potential for heat production by retrofitting abandoned gas wells into geothermal wells. Qingdao: China University of Petroleum (East China). Retrieved from PlosOne.
Zhang LY (2008) Energy from abandoned oil and gas reservoirs. SPE Association, Pacific oil and gas conference and exhibition. Perth: Society of Petroleum Engineers.

Zhang Q, Huang Z, Yao J, Wang Y, Li Y (2017) Multiscale mimetic method for two-phase flow in fractured media using embedded discrete fracture model. Adv Water Resour 107:170-180

Zhu GP, Yao J, Sun H, Zhang M, Xie MJ, Sun ZX, Lu T (2016) The numerical simulation of thermal recovery based on hydraulic fracture heating technology in shale gas reservoir. J Nat Gas Sci Eng 28:305-316

Publisher's Note Springer Nature remains neutral with regard to jurisdictional claims in published maps and institutional affiliations. 